\title{
Photopolymerization of Methyl Methacrylate with 1-Benzyl- 1,4-dihydronicotinamide in the Presence of Carbon Tetrachloride
}

\author{
Shozo Shimada, Katsuhiko NaKagawa, ${ }^{*}$ and Kenzo TABUCHI* \\ Sun Friend Chemical Co., Ltd., 5-5 Nishitenma, 4-chome, Kita-ku, \\ Osaka 530, Japan \\ * Department of Industrial Chemistry, Niihama National College of Technology, \\ 7-1, Yagumo-cho, Niihama 792, Japan
}

(Received September 5, 1988)

\begin{abstract}
The photopolymerization of methyl methacrylate (MMA) with 1-benzyl-1,4dihydronicotinamide (BNAH) was investigated in the presence of $\mathrm{CCl}_{4}$. The rate of photopolymerization of MMA with $\mathrm{BNAH}$ was remarkably accelerated by the addition of $\mathrm{CCl}_{4}$. The fluorescence spectra of $\mathrm{BNAH}$ in the presence of various concentrations of $\mathrm{CCl}_{4}$ showed that the photoexcited BNAH (BNAH*) was quickly quenched by $\mathrm{CCl}_{4}$. The spectral change of BNAH$\mathrm{CCl}_{4}$ system during UV-irradiation indicated that the absorption band $\left(\lambda_{\max }, 350 \mathrm{~nm}\right)$ of $\mathrm{BNAH}$ disappeared and the pyridinium band appeared at $260 \mathrm{~nm}$. These results suggest that the polymerization is initiated by the following mechanism. Hydrogen transfers from $\mathrm{BNAH}^{*}$ to $\mathrm{CCl}_{4}$, and consequently 1-benzylnicotinamide radical (BNA*) and $\mathrm{CCl}_{3} \cdot$ are generated. The $\mathrm{BNA} \cdot$ quickly reacts with $\mathrm{CCl}_{4}$ to produce 1-benzylnicotinamide chloride $\left(\mathrm{BNA}^{+} \mathrm{Cl}^{-}\right)$together with $\mathrm{CCl}_{3}{ }^{\circ}$ radical. The produced $\mathrm{BNA}^{+} \mathrm{Cl}^{-}$also photodecomposes into $\mathrm{BNA} \cdot$ and $\mathrm{Cl} \cdot$ radical. The $\mathrm{CCl}_{3}{ }^{\cdot}$ and $\mathrm{Cl} \cdot$ are able to initiate the polymerization. This photopolymerization could be performed in aqueous-organic two-phase system, and three components $\mathrm{BNA}^{+} \mathrm{Cl}^{-}-\mathrm{Na}_{2} \mathrm{~S}_{2} \mathrm{O}_{4}-\mathrm{CCl}_{4}$ were found to act as a cyclic phase-transfer photoinitiator system.
\end{abstract}

KEY WORDS Photopolymerization / Methyl Methacrylate / 1-Benzyl-1,4dihydronicotinamide / 1-Benzylnicotinamide Chloride / Carbon Tetrachloride / Sodium Dithionite / Phase Transfer / Photoinitiator /

$\mathrm{NAD}^{+}$and $\mathrm{NADH}$, coenzymes of alcohol dehydrogenase, play an important role in biological redox systems. The details of their reactions in biological redox systems, however, have not been clarified, and several compounds, such as 1-benzyl-3-carbamoylpyridinium salt $\left(\mathrm{BNA}^{+}\right)$and 1-benzyl-1,4-dihydronicotinamide (BNAH), have been used as models of $\mathrm{NAD}^{+}$and NADH, respectively. The nonenzymatic reactions with these models are known to require a cofactor. For example, the reductions of carbonyl group with NADH models should be accelerated by metal ions, such as $\mathrm{Mg}^{2+}$ and $\mathrm{Zn}^{2+} \cdot{ }^{1-3} \mathrm{NADH}$ models could also be activated by irradiation with UV light. $^{4-6}$ As far as reported, ${ }^{7,8}$ a mechanism involving electron-proton-electron-transfer three-step processes may be dominant for nonenzymatic reaction with $\mathrm{NADH}$ models.

However, the actual features of the reaction with $\mathrm{NAD}^{+}$and NADH are still obscure. In the preceding paper, ${ }^{9}$ the authors carried out the photopolymerization of vinyl monomers in order to elucidate whether a radical intermediate was incorporated in the reaction system containing NADH. Methyl methacrylate (MMA) was photopolymerized well with BNAH and the polymerization was found to proceed in radical mechanism and to yield a low molecular weight polymer containing a 
terminal BNAH residue.

In the present study, $\mathrm{CCl}_{4}$ was added to the above polymerization system. 1-Benzylnicotinamide radical $(\mathrm{BNA} \cdot)$, generated in the photoinitiation step, attacked $\mathrm{CCl}_{4}$ molecule rather than the MMA monomer and the growing polymer radical, yielding both $\mathrm{BNA}^{+} \mathrm{Cl}^{-}$ and $\mathrm{CCl}_{3} \cdot$ radical. The $\mathrm{CCl}_{3} \cdot$ initiated the polymerization of MMA into high molecular weight polymer. MMA could also be photopolymerized with $\mathrm{BNAH}-\mathrm{CCl}_{4}$ in an aqueousorganic two-phase system. The details of the polymerization are presented in the following along with the photopolymerization of MMA with $\mathrm{BNA}^{+}-\mathrm{Na}_{2} \mathrm{~S}_{2} \mathrm{O}_{4}-\mathrm{CCl}_{4}$ in aqueousorganic two-phase system.

\section{EXPERIMENTAL}

\section{Materials}

MMA was purified by the usual method just before use. Water was deionized and distilled. 1-Benzylnicotinamide chloride $\left(\mathrm{BNA}^{+} \mathrm{Cl}^{-}\right)$ and 1-benzyl-1,4-dihydronicotinamide (BNA$\mathrm{H})$ were prepared by the procedure described in the literature. ${ }^{10}$ All other chemicals used in this study were of reagent grade.

\section{Photopolymerization}

Solution photopolymerization of MMA with $\mathrm{BNAH}-\mathrm{CCl}_{4}$ in dichloromethane was performed in a hard glass ampoule by irradiation with Toshiba Fluorescent Chemical Lamp FL-20SBL $\left(20 \mathrm{~W}, \lambda_{\max } 360 \mathrm{~nm}\right)$. The detail procedure is described in the the previous paper. ${ }^{11}$

Photopolymerization of MMA with $\mathrm{BNA}^{+}$ $\mathrm{Na}_{2} \mathrm{~S}_{2} \mathrm{O}_{4}-\mathrm{CCl}_{4}$ in aqueous-organic, two-phase system was performed by photochemical reaction apparatus, which was also described in detail in the previous paper. ${ }^{12}$ A $150 \mathrm{~cm}^{3}$ reaction vessel was charged with $20 \mathrm{~cm}^{3}$ of MMA solution containing $\mathrm{CCl}_{4}(10 \mathrm{mmol})$ and $80 \mathrm{~cm}^{3}$ of aqueous solution containing $\mathrm{BNA}^{+} \mathrm{Cl}^{-} \quad(0.1 \mathrm{mmol}), \quad \mathrm{Na}_{2} \mathrm{~S}_{2} \mathrm{O}_{4} \quad(45 \mathrm{mmol})$ and $\mathrm{Na}_{2} \mathrm{CO}_{3}(45 \mathrm{mmol})$. The contents in the reaction vessel had pure nitrogen bubbled through them followed by irradiation with a Fuji Glass High Pressure Mercury Lamp HL$100(100 \mathrm{~W})$. The reaction mixture was then poured into a large quantity of methanol and the precipitated polymer was dried in vacuo.

\section{Measurements}

UV and Fluorescence spectra were recorded on JASCO UVIDEC-1 and JASCO FP-550 spectrometers, respectively.

\section{RESULTS AND DISCUSSION}

Photopolymerization of MMA with BNAH in the Presence of $\mathrm{CCl}_{4}$

Photopolymerization of MMA with BNAH in the presence of $\mathrm{CCl}_{4}$ proceeded faster than that with $\mathrm{BNAH}$ or $\mathrm{CCl}_{4}$ alone (Figure 1) and yielded a polymer of high molecular weight $\left(\bar{M}_{n} \geqq 100,000\right)$. In order to clarify the effect of $\mathrm{CCl}_{4}$-addition on the polymerization system, fluorescence spectra of BNAH excited with $350 \mathrm{~nm}$ light were measured in the presence of

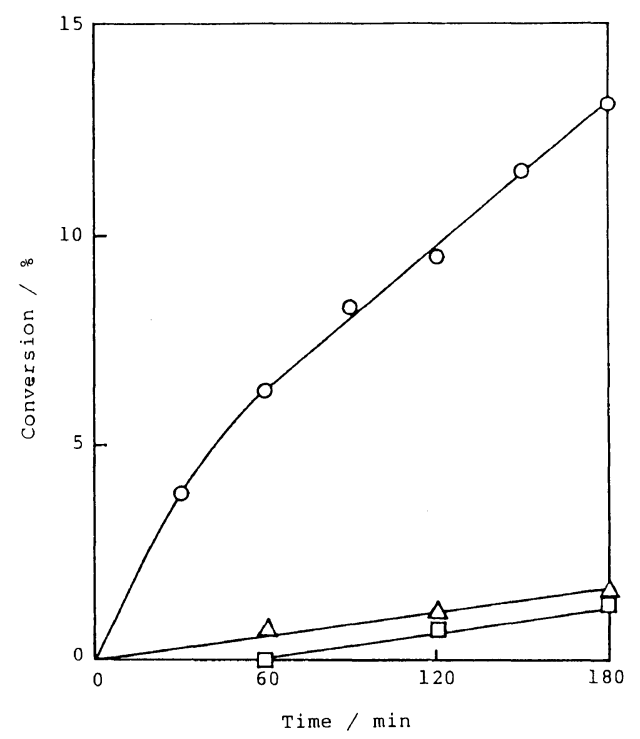

Figure 1. Photopolymerization of MMA with $\mathrm{BNAH}$ in the presence of $\mathrm{CCl}_{4}$ : $\mathrm{MMA}, 5 \mathrm{~cm}^{3}$; solvent, $\mathrm{CH}_{2} \mathrm{Cl}_{2}$; $O$, BNAH $1 \times 10^{-3} \mathrm{~mol} \mathrm{dm}^{-3}$ and $\mathrm{CCl}_{4} 1 \times 10^{-2}$ $\mathrm{moldm}{ }^{-3} ; \triangle$, BNAH $1 \times 10^{-3} \mathrm{moldm}^{-3} ; \square, \mathrm{CCl}_{4}$ $1 \times 10^{-2} \mathrm{~mol} \mathrm{dm}^{-3}$; temp, $303 \mathrm{~K}$. 


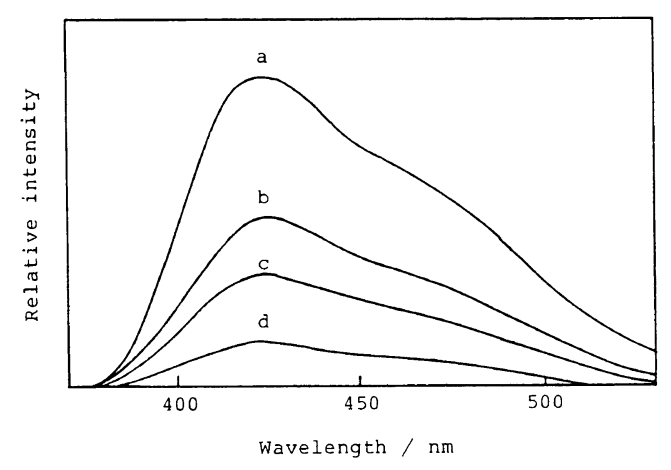

Figure 2. Fluorescence spectra of $\mathrm{BNAH}$ in $\mathrm{CH}_{2} \mathrm{Cl}_{2}$ in the presence of $\mathrm{CCl}_{4}$ : BNAH, $1 \times 10^{-4} \mathrm{~mol} \mathrm{dm}^{-3} ; \mathrm{CCl}_{4}$ $\left(\mathrm{mol} \mathrm{dm}^{-3}\right)$, a, $0 ; \mathrm{b}, 0.10 ; \mathrm{c}, 0.25 ; \mathrm{d}, 0.50 ; \lambda_{\mathrm{ex}}, 350 \mathrm{~nm}$.

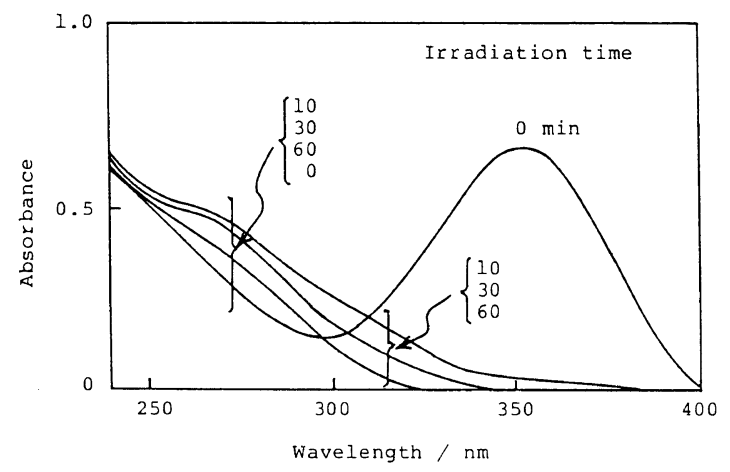

Figure 3. Spectral change by UV-irradiation for BNAH- $\mathrm{CCl}_{4}$ system in $\mathrm{CH}_{2} \mathrm{Cl}_{2}$.

$\mathrm{CCl}_{4}$. The spectra indicated that $\mathrm{CCl}_{4}$ quenched the excited BNAH (BNAH*) (Figure 2). In the preceding paper, ${ }^{9}$ the authors reported that MMA was able to quench BNAH*. The former was found to quench the excited BNAH about ten times faster than the latter.

The possibility of producing $\mathrm{BNA}^{+} \mathrm{Cl}^{-}$ from $\mathrm{BNAH}$ in the photolysis of $\mathrm{BNAH}-\mathrm{CCl}_{4}$ system was examined by spectral change during UV-irradiation as shown in Figure 3. After 10 minutes-irradiation, the absorption band $\left(\lambda_{\max } 350 \mathrm{~nm}\right)$ of BNAH disappeared, whereas the bands of the pyridinium ring and pyridinium complex appeared at 260 and $320 \mathrm{~nm}$, respectively. In the absence of $\mathrm{CCl}_{4}$, such a spectral change was very slow.

These results suggest the following photoinitiation mechanism.

$$
\begin{aligned}
& \mathrm{BNAH} \stackrel{h v}{\longrightarrow} \mathrm{BNAH}^{*} \\
& \mathrm{BNAH}^{*}+\mathrm{CCl}_{4} \stackrel{\begin{array}{l}
\text { hydrogen } \\
\text { transfer }
\end{array}}{\mathrm{BNA} \cdot+\mathrm{CCl}_{3} \cdot+\mathrm{HCl}} \\
& \mathrm{BNA} \cdot+\mathrm{CCl}_{4} \stackrel{\text { fast }}{\longrightarrow} \mathrm{BNA}^{+} \mathrm{Cl}^{-}+\mathrm{CCl}_{3} \cdot
\end{aligned}
$$

Equation 1 expresses photo-excitation of BNAH and eq 2 expresses hydrogen transfer from $\mathrm{BNAH}^{*}$ to $\mathrm{CCl}_{4}$. The generated $N$ benzylnicotinamide radial (BNA·) quickly reacts with $\mathrm{CCl}_{4}$ to product $\mathrm{BNA}^{+} \mathrm{Cl}^{-}$together with $\mathrm{CCl}_{3} \cdot$ (eq 3). The $\mathrm{CCl}_{3} \cdot$ is known to initiate the polymerization of MMA. The produced $\mathrm{BNA}^{+} \mathrm{Cl}^{-}$also photoinitiated the polymerization of MMA in the presence of $\mathrm{CCl}_{4}$ as well as 1-benzylpyridinium bromide ${ }^{11}$ and chloride. ${ }^{13}$ The mechanism of photopolymerization with $\mathrm{BNA}^{+} \mathrm{Cl}^{-}-\mathrm{CCl}_{4}$ may be expressed as follows:

$$
\begin{aligned}
& \mathrm{BNA}^{+} \mathrm{Cl}^{-} \stackrel{h v}{\longrightarrow} \mathrm{BNA} \cdot+\mathrm{Cl} \cdot \\
& \mathrm{R} \cdot\left(\mathrm{CCl}_{3} \cdot \text { or } \mathrm{Cl} \cdot\right)+\mathrm{M} \longrightarrow \mathrm{R}-\mathrm{M} \cdot \\
& \mathrm{R}-\mathrm{M}_{n} \cdot+\mathrm{M} \longrightarrow \mathrm{R}-\mathrm{M}_{n+1} \cdot \\
& \mathrm{R}-\mathrm{M}_{n} \cdot+\mathrm{R}-\mathrm{M}_{m} \cdot \longrightarrow \\
& \quad \mathrm{R}-\mathrm{M}_{n+m}-\mathrm{R} \text { or } \mathrm{R}-\mathrm{M}_{n}+\mathrm{R}-\mathrm{M}_{m}
\end{aligned}
$$

Photopolymerization of $\mathrm{MMA}$ with $\mathrm{BNA}^{+} \mathrm{Cl}^{-}-$ $\mathrm{Na}_{2} \mathrm{~S}_{2} \mathrm{O}_{4}-\mathrm{CCl}_{4}$ in Aqueous-Organic, TwoPhase System

The photopolymerization described in the preceding section could be performed in an aqueous-organic two-phase system. $\mathrm{BNA}^{+} \mathrm{Cl}^{-}$ produced in organic phase may transfer to aqueous phase and if alkaline solution of $\mathrm{Na}_{2} \mathrm{~S}_{2} \mathrm{O}_{4}$ is present, it may be reduced to $\mathrm{BNAH}$, which is able to transfer to the organic phase. Thus, the cyclic phase-transfer photoinitiator system shown in Scheme 1 is expected.

MMA was photopolymerized with $\mathrm{BNA}^{+}$$\mathrm{Cl}^{-}-\mathrm{Ba}_{2} \mathrm{~S}_{2} \mathrm{O}_{4}-\mathrm{CCl}_{4}$ in an MMA-water twophase system. The results in Table I show that 


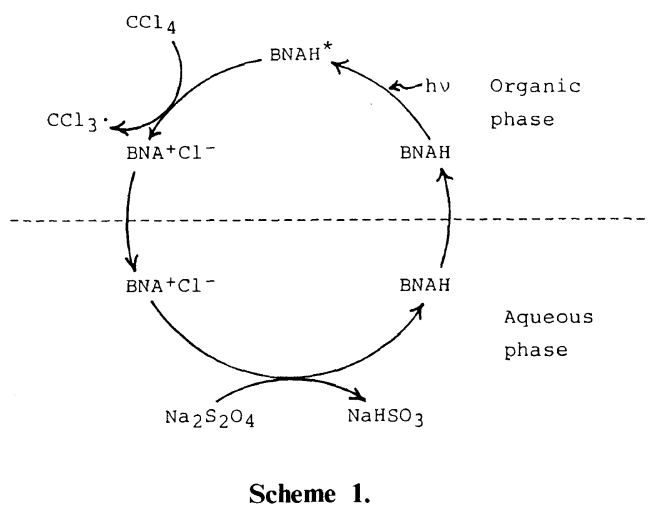

Table I. Photopolymerization of MMA with $\mathrm{BNA}^{+} \mathrm{Cl}^{-}-\mathrm{Na}_{2} \mathrm{~S}_{2} \mathrm{O}_{4}-\mathrm{CCl}_{4}$ in aqueousorganic, two-phase system ${ }^{a}$

\begin{tabular}{|c|c|c|c|c|}
\hline $\mathrm{BNA}^{+} \mathrm{Cl}^{-}$ & $\mathrm{CCl}_{4}$ & $\mathrm{Na}_{2} \mathrm{~S}_{2} \mathrm{O}_{4}$ & $\mathrm{Na}_{2} \mathrm{CO}_{3}$ & Conversion \\
\hline $\mathrm{mmol}$ & $\mathrm{mmol}$ & $\mathrm{mmol}$ & $\mathrm{mmol}$ & $\%$ \\
\hline - & - & - & - & 1.10 \\
\hline 1 & - & - & - & 0.66 \\
\hline - & 36 & - & - & 0.21 \\
\hline - & - & 90 & 90 & 3.29 \\
\hline 1 & 36 & - & - & 0.33 \\
\hline 1 & - & 90 & 90 & 1.20 \\
\hline - & 36 & 90 & 90 & 5.12 \\
\hline 1 & 36 & 90 & 90 & 19.57 \\
\hline
\end{tabular}

a MMA, $20 \mathrm{~cm}^{3} ; \mathrm{H}_{2} \mathrm{O}, 80 \mathrm{~cm}^{3}$; temp, $303 \mathrm{~K}$; time, $1 \mathrm{~h}$; blowing rate of $\mathrm{N}_{2}, 0.5 \mathrm{~cm}^{3} \mathrm{~s}^{-1}$.

the photopolymerization proceeded slowly in the absence of any one of these three components.

In order to elucidate the mechanism kinetically, the photopolymerization of MMA with $\mathrm{BNA}^{+} \mathrm{Cl}^{-}-\mathrm{Na}_{2} \mathrm{~S}_{2} \mathrm{O}_{4}-\mathrm{CCl}_{4}$ was carried out at various feeding ratios of the initiator components. The results indicated the rate of polymerization $\left(R_{\mathrm{p}}\right)$ to be proportional to the square root of the concentration of each of the three initiator components, $\mathrm{BNA}^{+} \mathrm{Cl}^{-}$, $\mathrm{Na}_{2} \mathrm{~S}_{2} \mathrm{O}_{4}$, and $\mathrm{CCl}_{4}$ (Figure 4-6). When $\mathrm{BNA}^{+} \mathrm{Cl}^{-}$was fed beyond $0.5 \mathrm{mmol}, R_{\mathrm{p}}$ did not increase and became constant (Figure 4). This implies that the entire amount of $\mathrm{BNA}^{+} \mathrm{Cl}^{-}$charged in aqueous phase is reduced to $\mathrm{BNAH}$ by $\mathrm{Na}_{2} \mathrm{~S}_{2} \mathrm{O}_{4}$ but that only a

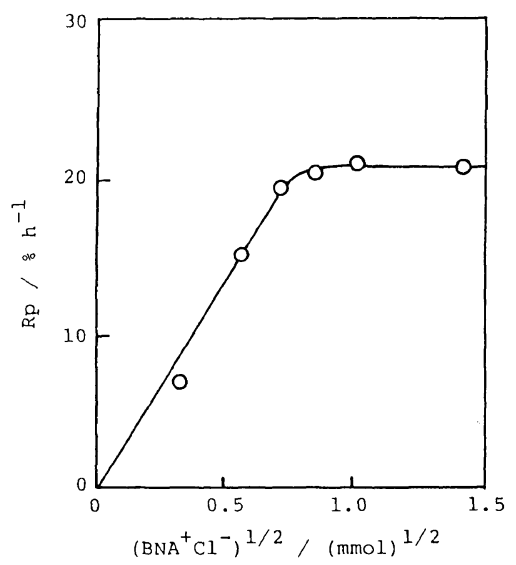

Figure 4. Relation of $R_{\mathrm{p}}$ vs. $\left(\mathrm{BNA}^{+} \mathrm{Cl}^{-}\right)^{1 / 2}$ for the photopolymerization of $\mathrm{MMA}$ with $\mathrm{BNA}^{+} \mathrm{Cl}^{-}$$\mathrm{Na}_{2} \mathrm{~S}_{2} \mathrm{O}_{4}-\mathrm{CCl}_{4}$ in aqueous-organic two-phase system: MMA, $20 \mathrm{~cm}^{3} ; \mathrm{H}_{2} \mathrm{O}, \quad 80 \mathrm{~cm}^{3} ; \quad \mathrm{Na}_{2} \mathrm{~S}_{2} \mathrm{O}_{4}, 45 \mathrm{mmol}$; $\mathrm{Na}_{2} \mathrm{CO}_{3}, 45 \mathrm{mmol} ; \mathrm{CCl}_{4}, 10 \mathrm{mmol}$; temp, $303 \mathrm{~K}$.

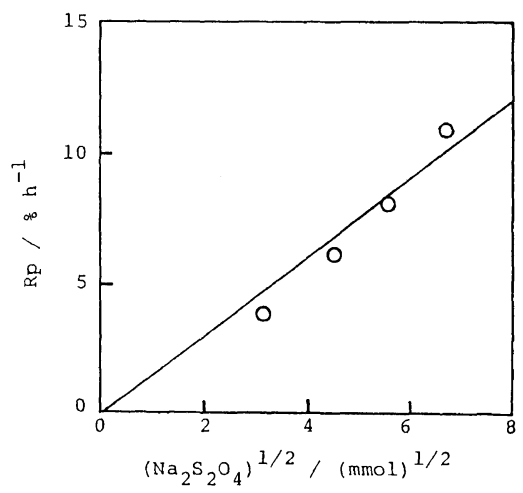

Figure 5. Relation of $R_{\mathrm{p}}$ vs. $\left(\mathrm{Na}_{2} \mathrm{~S}_{2} \mathrm{O}_{4}\right)^{1 / 2}$ for the photopolymerization of $\mathrm{MMA}$ with $\mathrm{BNA}^{+} \mathrm{Cl}^{-}$ $\mathrm{Na}_{2} \mathrm{~S}_{2} \mathrm{O}_{4}-\mathrm{CCl}_{4}$ in aqueous-organic two-phase system: MMA, $20 \mathrm{~cm}^{3} ; \mathrm{H}_{2} \mathrm{O}, 80 \mathrm{~cm}^{3} ; \mathrm{BNA}^{+} \mathrm{Cl}^{-}, 0.1 \mathrm{mmol}$; $\mathrm{Na}_{2} \mathrm{CO}_{3}, 45 \mathrm{mmol} ; \mathrm{CCl}_{4}, 10 \mathrm{mmol}$; temp, $303 \mathrm{~K}$.

constant part of produced BNAH is solubilized in the organic phase.

When BNAH was fed instead of $\mathrm{BNA}^{+} \mathrm{Cl}^{-}$ in this two-phase system, the polymerization proceeded as well as with $\mathrm{BNA}^{+} \mathrm{Cl}^{-}$, and the relations of $R_{\mathrm{p}} v s$. (BNAH) $)^{1 / 2}$ and $R_{\mathrm{p}} v s$. $\left(\mathrm{BNA}^{+} \mathrm{Cl}^{-}\right)^{1 / 2}$ are compared in Figure 7. According to the experimental conditions, both linear relations of $R_{\mathrm{p}}$ vs. $(\mathrm{BNAH})^{1 / 2}$ and $\left(\mathrm{BNA}^{+} \mathrm{Cl}^{-}\right)^{1 / 2}$ should have the same slope, but the slope of the former was far larger than that 


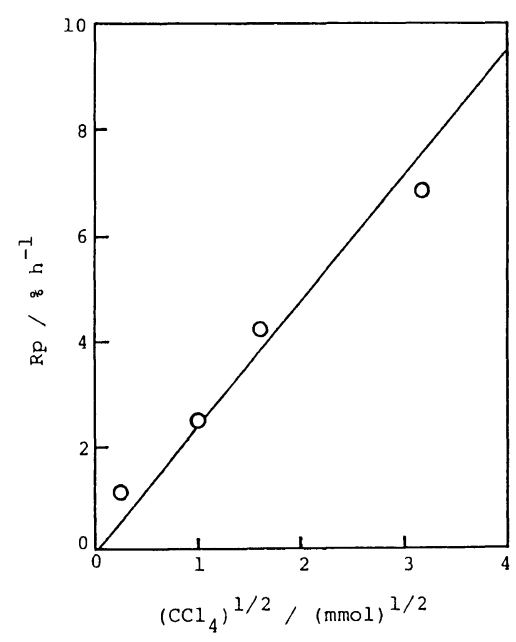

Figure 6. Relation of $R_{\mathrm{p}} v s$. $\left(\mathrm{Na}_{2} \mathrm{CO}_{3}\right)^{1 / 2}$ for the photopolymerization of MMA with $\mathrm{BNA}^{+} \mathrm{Cl}^{-}-\mathrm{Na}_{2} \mathrm{~S}_{2} \mathrm{O}_{4}-$ $\mathrm{CCl}_{4}$ in aqueous-organic two-phase system: MMA, $20 \mathrm{~cm}^{3} ; \mathrm{H}_{2} \mathrm{O}, 80 \mathrm{~cm}^{3} ; \mathrm{BNA}^{+} \mathrm{Cl}^{-}, 0.1 \mathrm{mmol} ; \mathrm{Na}_{2} \mathrm{~S}_{2} \mathrm{O}_{4}$, $45 \mathrm{mmol} ; \mathrm{CCl}_{4}, 10 \mathrm{mmol}$; temp, $303 \mathrm{~K}$.

of the latter. As shown in Scheme 1, BNAH added to the organic phase was consumed by irradiation to $\mathrm{BNA}^{+} \mathrm{Cl}^{-}$, which was reduced to $\mathrm{BNAH}$ in the aqueous phase. In the stationary state of this cyclic phase-transfer initiation process, the concentration of $\mathrm{BNAH}$ is controlled by the experimental conditions. Therefore, at the initial stage of the polymerization, the concentration of BNAH in organic phase should be higher than that at the stationary state. On feeding much BNAH beyond $0.1 \mathrm{mmol}, R_{\mathrm{p}}$ decreased to a constant value. The apparent maximum of $R_{\mathrm{p}}$ implies that BNAH contributes not only to the initiation but also to the termination of what authors should specify as described in the preceding paper. ${ }^{9}$ The concentration of BNAH at the constant $R_{\mathrm{p}}$ seemes to depend on the solubility of BNAH in the organic phase as mentioned above.

Acknowledgements. The authors are grateful to Dr. N. Sakota, Sakota Chemical De-

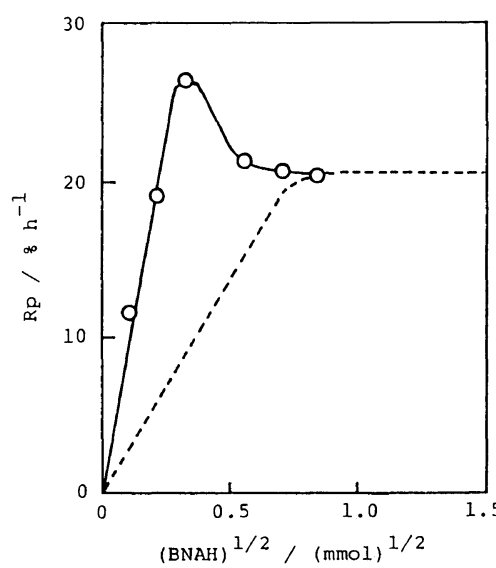

Figure 7. Relation of $R_{\mathrm{p}} v s$. (BNAH) $)^{1 / 2}$ for the photopolymerization of MMA with BNAH- $\mathrm{Na}_{2} \mathrm{~S}_{2} \mathrm{O}_{4}-\mathrm{CCl}_{4}$ in aqueous-organic two-phase system: $\mathrm{MMA}, 20 \mathrm{~cm}^{3}$; $\mathrm{H}_{2} \mathrm{O}, 80 \mathrm{~cm}^{3} ; \mathrm{Na}_{2} \mathrm{~S}_{2} \mathrm{O}_{4}, 45 \mathrm{mmol} ; \mathrm{Na}_{2} \mathrm{CO}_{3}, 45 \mathrm{mmol}$; $\mathrm{CCl}_{4}, 10 \mathrm{mmol}$; temp, $303 \mathrm{~K}$. Dotted line indicates the relation of $R_{\mathrm{p}} v s$. $\left(\mathrm{BNA}^{+} \mathrm{Cl}^{-}\right)^{1 / 2}$ in Figure 4.

velopement and Research Institute Co., Ltd., for his valuable comments and helpful advice.

\section{REFERENCES}

1. A. Ohno, H. Yamamoto, and S. Oka, J. Am. Chem. Soc., 103, 2041 (1981).

2. S. Fukuzumi, N. Nishizawa, and T. Tanaka, Chem. Lett., 1755 (1983).

3. Y. Murakami, Y. Aoyama, and J. Kikuchi, Bull. Chem. Soc. Jpn., 55, 2898 (1982).

4. Y. Ohnishi, M. Kagami, and A. Ohno, Chem. Lett., 125 (1975).

5. S. Fukuzumi, K. Hironaka, and T. Tanaka, Chem. Lett., 1583 (1982).

6. C. Pac, Y. Miyauchi, O. Ishitani, M. Ihara, M. Yasuda, and H. Sakurai, J. Org. Chem., 49, 26 (1984).

7. A. Ohno, T. Shio, H. Yamamoto, and S. Oka, J. Am. Chem. Soc., 103, 2045 (1981).

8. L. L. Miller and J. R. Valentine, J. Am. Chem. Soc., 110, 3982 (1988).

9. K. Tabuchi and N. Sakota, Polym. J., 17, 537 (1985).

10. Y. Kurusu, K. Nakajima, and M. Okawara, Kogyo Kagaku Zasshi, 71, 934 (1968).

11. K. Tabuchi and N. Sakota, Polym. J., 15, 57 (1983).

12. K. Tabuchi and N. Sakota, Polym. J., 15, 713 (1983).

13. K. Tabuchi and N. Sakota, Polym. J., 15, 569 (1983). 